\title{
The Kidney Genetics Clinic: delivering precision medicine for kidney patients
}

\author{
Joaquim Calado $1,6,{ }^{*}$ (iD), Rui Barata1,* iD, Rita Lucas ${ }^{2}$ (iD), Telma Francisco 3 iD), Rui Gonçalves ${ }^{4}$, Nuno Carrilho Ribeiro 5 iD, Fernando Nolasco ${ }^{1,7}$ (DD \\ ${ }^{1}$ Nephrology Department, Centro Hospitalar e Universitário de Lisboa Central, Lisbon, Portugal \\ 2 Pharmaceutical Department, Centro Hospitalar e Universitário de Lisboa Central, Lisbon, Portugal \\ 3 Pediatrics Department, Centro Hospitalar e Universitário de Lisboa Central, Lisbon, Portugal \\ ${ }^{4}$ Genetics Department, Centro Hospitalar e Universitário de Lisboa Central, Lisbon, Portugal \\ ${ }^{5}$ Radiology Department, Centro Hospitalar e Universitário de Lisboa Central, Lisbon, Portugal \\ ${ }^{6}$ Centre for Toxicogenomics and Human Health (ToxOmics), Genetics, Oncology and Human Toxicology, Nova Medical School/Faculdade de Ciências Médicas, Universidade \\ Nova de Lisboa, Lisbon, Portugal \\ ${ }^{7}$ CEDOC, Chronic Diseases Research Centre, Nova Medical School/Faculdade de Ciências Médicas, Universidade Nova de Lisboa, Lisbon, Portugal \\ * Corresponding authors
}

\section{ABSTRACT}

Molecular genetic testing in human traits has traditionally relied on affiliated academic facilities, been focused on specific phenotypes and supported by research funding. We report the experience of the Kidney Genetics Clinic ("consulta de Doenças Renais Hereditárias") for the past 5 years, a period during which we have outsourced genetic testing. We evaluated the impact of molecular testing in patients' care, but we also assessed disease-specific imaging procedures and medicines provided.

During the study period, 293 individuals were evaluated. Autosomal Dominant Polycystic Kidney Disease was the most frequent diagnosis (61.8\%). In 125 patients, a genetic test was available, and for 76 of these (60.8\%) a pathogenic/likely pathogenic variant was identified. Depending on the phenotype, the mutation detection rate ranged from 100\% (Tuberous Sclerosis Complex) to 15.4\% (Autosomal Dominant Tubulointerstitial Kidney Disease). The impact of genetic testing on patients' diagnosis and treatments is discussed. Total kidney volume was calculated in 6 patients with Autosomal Dominant Polycystic Kidney Disease and the combined volume for selected angiomyolipoma monitored in 3 individuals with the Tuberous Sclerosis Complex. Currently, 4 patients are being treated with Everolimus/Votubia ${ }^{\mathrm{TM}}, 3$ with Eculizumab/Soliris ${ }^{\mathrm{TM}}$ and 2 with Tolvaptan/Jinarc ${ }^{\mathrm{TM}}$.

Our results demonstrate the feasibility of genetic molecular testing in a clinical setting while relying on outsourced sites for gene testing. We emphasize that it was only because the Kidney Genetics Clinic was given the opportunity to look after several patients affected by the same specific orphan or rare diseases (cohort enrichment) that we were able to improve diagnostic skills and deliver personalized medicines.

Key-words: genetics, inherited kidney disorders, molecular testing, rare kidney diseases, precision medicine.

(C) 2021 Portuguese Journal of Nephrology \& Hypertension. Published by Publicações Ciência \& Vida This is an open access article under the CC BY-NC-ND license (http://creativecommons.org/licenses/by-nc-nd/4.0/).

\section{BACKGROUND}

In 2006 we implemented at Centro Hospitalar Universitário de Lisboa Central (CHULC) a Kidney Genetics Clinic (KGC) with an initial focus on autosomal dominant polycystic kidney disease (ADPKD). With the coming of age for novel ADPKD therapies, our main objectives were the following: i) gain expertise in the management of ADPKD patients (including molecular diagnosis); ii) gaining knowledge on total kidney volume as a biomarker; iii) develop a cohort that could be useful in future clinical trial settings.

In those days, the Sanger sequencing days, molecular diagnosis was not easily available in Portugal. In particular, the PKD1 gene was (and still remains) a very difficult gene to sequence. The idea was to develop molecular genetics skills in our Laboratório de Morfologia
Renal and provide indirect genetic testing for ADPKD. The methodology relied on the co-segregation analysis of the disease with several polymorphic microsatellite repeats in closed proximity (linked) to the causal gene. As expected, the limitations soon became apparent: the test required multigenerational families and needed as many as possible (affected and non-affected) members available for segregation studies; and although in some families we could identify and trace the ancestral chromosome it did not allow us to identify the actual mutation, the purpose of the whole thing being hard to explain to colleagues and, most importantly, to families.

On the other hand, we successfully set up a computerized tomography (CT) scan-based segmentation methodology for total kidney volume (TKV) determination. A pilot study was performed and the results presented in $2008^{1}$. Finally, regarding clinical trials, 
and based on the literature at the time, an Investigator Originated Proposal (IOP) entitled "National Multicenter Sirolimus (SRL) Evaluation Trial for Autosomal Dominant Polycystic Kidney Disease (ADPKD): a new use for an old drug?" was submitted to the Wyeth Pharmaceuticals. Soon after the IOP submission, Pfizer acquired Wyeth and later on it became apparent that SRL was not effective in patients with ADPKD².

The absence, at both CHULC and the medical school we are affiliated to, of a molecular genetics diagnostic laboratory has been a major limitation to our program. This was one of the reasons we restricted our approach to linkage analysis in ADPKD, the most prevalent inherited kidney disease, since it was the only molecular approach we could afford. Apart from ADPKD, the other mendelian traits we performed molecular diagnosis concerned the identification of the NPHP1 "common" deletion in homozigocity for Nephronophthisis (NPH), using reagents that the corresponding author had brought along from his PhD studies ${ }^{3}$, the direct sequencing of the coding region of the SLC5A2 gene in Familial Renal Glucosuria (FRG), a major investigational subject for the authors ${ }^{4}$, as well for the UMOD gene in cases of Familial Juvenile Hyperuricemic Nephropathy (FJHN), for which research funds were also available.

With the growing awareness of the clinic's activity, an increasing number of adult patients with other inherited kidney diseases was being referred. Most importantly, the widespread use of next generation sequencing (NGS) made commercial gene-panel testing widely available and affordable. In light of these developments the scope of our activity broadened and now encompasses a wide range of inherited renal diseases. For these, expertise management is provided, including phenotype-driven panel testing outsourced to commercial as well as academic institutions.

It is the purpose of the current manuscript to review the KGC's activity for the past 5 years. We will emphasize the impact of genetic testing in patients but also address the role of renal imaging and target pharmacological interventions already available for some inherited renal diseases.

\section{MATERIAL AND METHODS}

We reviewed the clinic's activity from the $1^{\text {st }}$ of January of 2016 until the $31^{\text {st }}$ of December of 2020 , and selected the following outcomes:

i) number, gender and age of individuals referred and number of appointments;

ii) clinical diagnosis, genetic tests requested and the reported results by gene;

iii) number of specific imaging procedures requested: TKV for ADPKD and angiomyolipoma (AML) volume assessment for the Tuberous Sclerosis Complex (TSC);

iv) number of individuals selected for specific therapeutics.

Phenotypes were named after the Orphanet, assessed via the portal site (https://www.orpha.net), which allows codes for phenotypes, as opposed to on-line Mendelian Inheritance in Man
(OMIM) (https://omim.org) that is often gene-ontology based for the more genetically heterogenous clinical traits (e.g. ADPKD). Disease definition followed formal diagnostic criteria whenever available: ADPKD $^{5}$, Alport Syndrome (AS) ${ }^{6}$, Autosomal Dominant Tubulointerstitial Kidney Disease (ADTKD) ${ }^{7}$, atypical Hemolytic Uremic Syndrome $(\mathrm{aHUS})^{8}, \mathrm{TSC}^{9}, \mathrm{FRG}^{4}$, Gitelman Syndrome $(\mathrm{GS})^{10}$ and Bartter Syndrome (BS) ${ }^{11}$. Also, and regarding the adult population with Genetic Steroid Resistant Nephrotic Syndrome (gSRNS, ORPHA code 656), focal and segmental glomerulosclerosis (FSGS) is the most frequent histopathological finding. Likewise, and in contrast to the pediatric setting, autosomal dominant forms prevail. As such, we have included probands from pedigrees having familial cases (even if steroid resistance was not assessed) as well those seemingly sporadic FSGS young adult cases displaying primary resistance to steroids. In all circumstances the histopathology of FSGS had to be documented: if not in the proband, at least in an affected family member. For that reason, we opted for the denomination of FSGS instead of gSRNS.

It is our intention only to report pathogenic or likely pathogenic allelic variants, according to the American College of Medical Genetics and Genomics ${ }^{12}$. But we must acknowledge that these guidelines have not always been around and so it is possible that variants of unknown significance may have been included for earlier cases.

TKV, as a biomarker for ADPKD, was assessed by a low dose radiation (5-10 mSv) CT scan protocol with measurement of each kidney's sagittal and coronal lengths as well width and depth by a single radiologist experienced with ADPKD. Height adjusted TKV (ht TKV) was determined using the ellipsoid formula $(\pi / 6 \times L \times W x D)$ and the Mayo clinic imaging classification algorithm for ADPKD (https://www.mayo. edu/research/documents/pkd-center-adpkd-classification/doc-20094754). For AML evaluation in TSC and patient selection for the treatment with Everolimus/Votubia ${ }^{\mathrm{TM}}$ or follow-up, a protocol using Magnetic Resonance Imaging (MRI) was develop where up to 5 lesions are selected, the volume of each determined by ellipsoid method ( 3 orthogonal measures for each $\mathrm{AML}$ ) at week $\mathrm{t} 0, \mathrm{t} 12, \mathrm{t} 48$ and annually thereafter. As we gained experience with MRI for monitoring AML, the protocol was changed and MRIs are now performed at week t0, t24 and annually after.

Finally, and concerning targeted and disease specific therapies for inherited renal disease already provided by CHULC/KGC, we have reviewed the data for patients that were selected and have initiated therapy with Everolimus/Votubia ${ }^{\mathrm{TM}}$ (TSC), Eculizumab/Soliris ${ }^{\mathrm{TM}}$ (aHUS) and Tolvaptan/Jinarc ${ }^{\mathrm{TM}}$ (ADPKD).

\section{RESULTS}

\section{Structure of the kidney genetic clinic}

A single nephrologist with an interest in inherited renal diseases and with formal training in molecular genetics is responsible for the appointments as well all the necessary bench work. In addition, residents from the genetic and nephrology fellowships have joined the program for periods of 3 months as part of their postgraduate training. A part-time administrative support is also available. 
Two weekly dedicated genetic clinic sessions are scheduled, encompassing 8-10 appointments per week and accounting for a total of 10 hours. An additional 2 hours are allocated to sample collection, DNA extraction, storage and submission to outsourced genetic testing sites, contacting laboratories for results discussion and panel optimization, as well as other administrative work.

A recent and important feature of the KGC is the multidisciplinary rounds between adult and pediatric nephrologists and a geneticist that take place every other week to discuss the most difficult cases, update the genetic testing results and develop multigene panel for NGS sequencing.

Figure 1 depicts the structure of KGC. Although occasional patients are referred from other hospitals, the majority are from within CHULC, in particular from the pediatric and adult nephrology departments. The KGC relies on the genetic department of CHULC for formal genetic counselling and so all the genetic tests performed for KGC patients in that context are ordered by the genetics department. Also, many pediatric patients that have transitioned to the KGC have already been genotyped. The large majority of the genetic testing requested by KGC concerns diagnostic molecular confirmation in cases with atypical presentations, sporadic forms or if a phenocopy is suspected, as well when genotyping can help prognostication and patient selection for targeted therapies (Tolvaptan/Jinarc ${ }^{\mathrm{TM}}$ and living related donor organ transplantation).
Whenever possible, the most suitable proband within the affected family is the individual to be selected for genetic testing. This will be relevant in cases of $X$-linked Alport syndrome, where hemizygotic male patients with fully penetrant disease should be tested first, or in the adult setting of FSGS, where patients with a renal biopsy are eligible. Once the patient has given the informed consent, a blood sample is collected and DNA extracted from peripheral blood leucocytes that will be stored at -20 - $\mathrm{C}$ until a statement of responsibility is issued by the board of CHULC. Only then will the sample be sent to the commissioned genetic laboratory by mail. Extracting DNA in our own lab is most advantageous for patients since collecting a sample during the routine appointment will avoid a second visit once the statement of responsibility is issued. In addition, if there is need for a second round of testing for a different set of genes (either because novel genes were meanwhile found to be responsible for the phenotype or the latter was rechallenged by novel clinical data) the stored whole peripheral blood enables additional rounds of DNA extraction.

\section{Referrals, appointments and epidemiological data}

During the study period, 293 individuals were referred to the KGC. The average age and the number of appointments per patient were 46.8 years ( \pm 16.5 ) and $5.3( \pm 4.5)$, respectively, with $55.4 \%$ of the individuals being females.

\section{Figure 1}

Structure of the Kidney Genetics Clinic at CHULC. See text for details.

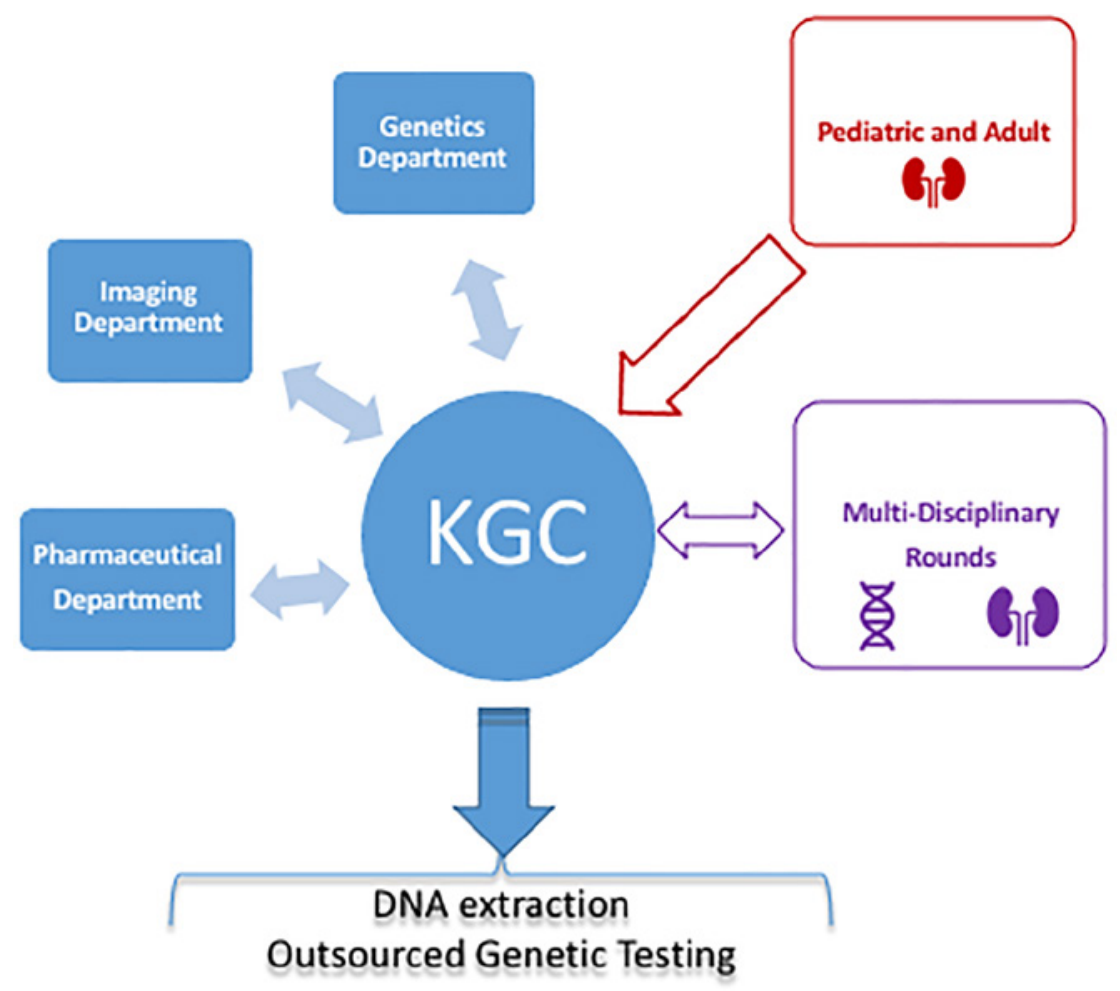




\section{Clinical and Genetic diagnosis}

Table 1 details the clinical diagnosis, gender and age for the entire KGC cohort as well for each of the 10 most prevalent observed inherited kidney disorders. For each diagnosis, the corresponding Orphanet code is displayed. In the category of "Others" there are 19 referrals that include genetically characterized cystic phenotypes [eg, Bardet-Biedl Syndrome (1) or Nephronophthisis (NPH) (1)] as well nephrolithiasis cases (3) that remained uncharacterized after phenotypic evaluation and for whom the caring physician pursed a genetic cause.

In Table 2, and for each clinical diagnosis, the number of genetic tests performed as well as their results assorted by gene are presented. For the entire KGC cohort of the 293 individuals censored, $42.7 \%$ had a genetic test performed, adding to a total of 125 individuals tested. For 76 of these $(60.8 \%$ of tested individuals), pathogenic or likely pathogenic alleles were identified and found to account for the phenotype. In particular, for recessive traits like Lissencephaly-8 syndrome (1), Hyper-IgD syndrome (1), Combined Oxidative Phosphorylation Deficiency-11 (1), BS (3), NPH (1) and AS of autosomal recessive inheritance (1) there was a requirement for the discovery of 2 pathogenic alleles in TMTC3, MVK, RMND1, BSND, CLCNKB, NPHP1 or COL4A3 genes, respectively. In the current analysis, each pair of alleles found in these recessive phenotypes was computed as single entry.

\section{Table 1}

Demographic data of the KGC cohort.

\begin{tabular}{|c|c|c|c|}
\hline & $\begin{array}{c}\text { Patients } \\
\mathrm{n} \text { (\% of } \\
\text { total) }\end{array}$ & $\begin{array}{l}\text { Age Years } \\
\text { mean (SD) }\end{array}$ & $\begin{array}{l}\text { Gender } \\
\text { F/M }\end{array}$ \\
\hline \multicolumn{4}{|l|}{ Total KGC Cohort } \\
\hline & $293(100)$ & $46.8(16.5)$ & $162 / 131$ \\
\hline \multicolumn{4}{|l|}{$\begin{array}{l}\text { Phenotype } \\
\text { (orpha code) }\end{array}$} \\
\hline $\begin{array}{l}\text { Autosomal Dominant Polycystic Kidney Disease } \\
\text { (730 - ADPKD) }\end{array}$ & $181(61.8)$ & $49.2(16.7)$ & $100 / 81$ \\
\hline $\begin{array}{l}\text { Alport Syndrome } \\
(63-A S)\end{array}$ & $20(6.8)$ & $36.3(11.8)$ & $13 / 7$ \\
\hline $\begin{array}{l}\text { Genetic Steroid-Resistant Nephrotic Syndrome } \\
(656-\text { gSRNS/FSGS })\end{array}$ & $18(6.1)$ & $45.7(18.8)$ & $15 / 3$ \\
\hline $\begin{array}{l}\text { Autosomal Dominant Tubulointerstitial } \\
\text { Kidney Disease } \\
\text { (730-ADTKD) }\end{array}$ & $14(4.8)$ & $56(13.3)$ & $6 / 8$ \\
\hline $\begin{array}{l}\text { Atypical Hemolytic Uremic Syndrome } \\
\text { (2134-aHUS) }\end{array}$ & $13(4.4)$ & $49.5(10)$ & $9 / 4$ \\
\hline $\begin{array}{l}\text { Tuberous Sclerosis Complex } \\
\text { (805-TSC) }\end{array}$ & $10(3.4)$ & $33.7(14.3)$ & $5 / 5$ \\
\hline $\begin{array}{l}\text { Familial Renal Glucosuria } \\
\text { (69076- FRG) }\end{array}$ & $7(2.4)$ & $44.7(19.3)$ & $1 / 6$ \\
\hline $\begin{array}{l}\text { Gitelman Syndrome } \\
\text { (358-GS) }\end{array}$ & $5(1.7)$ & $50(11.2)$ & $2 / 3$ \\
\hline $\begin{array}{l}\text { Distal Renal Tubular Acidosis } \\
\text { (18-dRTA) }\end{array}$ & $3(1)$ & $39.8(14.2)$ & $0 / 3$ \\
\hline $\begin{array}{l}\text { Bartter Syndrome } \\
(112-B S)\end{array}$ & $3(1)$ & $40(23.6)$ & $1 / 2$ \\
\hline Other & $19(6,5)$ & $35.3(10)$ & $11 / 8$ \\
\hline
\end{tabular}

*classification by clinical diagnosis according to Orphanet; \# see text for details.

\section{Imaging Procedures}

Ht TKV as a biomarker in ADPKD for renal prognostication and/ or patient selection for Tolvaptan/Jinarc ${ }^{\mathrm{TM}}$ therapy was requested in 4 patients. In two additional patients, CT scans performed in different setting (liver transplantation, hemorrhagic or infected cysts) also enabled ht TKV determination. Patients' age, gender, and serum creatinine for these 6 patients are presented in Table 3. As an example, Figure 2 displays the length measurements of the right kidney for the female patient aged 36, where axial, coronal and sagittal views are portraited.

For TSC, 3 individuals were assessed with MRI regarding AML. Figure 3 depicts an illustrative patient in whom our MRI protocol monitored 3 AML lesions before, during and after Everolimus/Votubia ${ }^{\mathrm{TM}}$ treatment.

\section{Disease specific and targeted therapies}

Everolimus/Votubia ${ }^{\mathrm{TM}}$ - in 2016 we treated our first TSC patient for AML. Since then, and until the $31^{\text {st }}$ of December 2020, 3 additional patients were recruited, including transitioning pediatric patients. Table 4 summarizes our treated TSC cohort.

Eculizumab/Soliris ${ }^{\mathrm{TM}}-3$ patients with aHUS were treated with anti $\mathrm{C} 5$ therapy during the study period. All had histopathologically documented thrombotic microangiopathy by means of a renal biopsy, all were NGS sequenced using a multigene panel targeting the alternative complement pathway system and all have had previous relapses. Table 5 depicts the major findings of the 3 individuals.

Tolvaptan/Jinarc ${ }^{\mathrm{TM}}-\mathrm{V} 2$ receptor antagonist therapy is the most recent disease specific therapy provided to CHULC patients. In 2020 we developed a protocol for Tolvaptan/Jinarc ${ }^{\text {TM }}$ treatment of ADPKD patients that incorporated the available guidelines (see discussion) and we screened our cohort for ADPKD individuals for treatment eligibility. The CHULC board approved treatment for the first 4 patients to be treated in 2021 and, at the time of this writing, 2 have already initiated treatment with Tolvaptan/Jinarc ${ }^{\mathrm{TM}}$. In Table 6 we report the phenotype and genotype (when available) in all 4 selected patients.

\section{DISCUSSION}

In the current analysis, we evaluated the KGC activity for the last 5 years. The range of phenotypes evaluated are in line with what has been reported by Lundquist AL et al. ${ }^{13}$ while describing a similar clinic at the Massachusetts General Hospital (Boston, USA) but with a cohort that is significantly smaller than ours. With the advent of NGS it became possible for institutions not associated with genetic testing laboratories to provide molecular genetic diagnosis for their patients in a manner independent of research funding availability. In Table 7 we provide a list of the most frequently outsourced academic and commercial laboratories that provide genetic testing to our patients. 


\section{Table 2}

Molecular genetic testing results.

\begin{tabular}{|c|c|c|c|c|c|}
\hline & $\begin{array}{c}\text { Patient } \\
\mathrm{n}\end{array}$ & $\begin{array}{l}\text { Requested Tests } \\
\mathrm{n} \text { (\% of patients) }\end{array}$ & $\begin{array}{l}\text { Pathogenic/Likely Pathogenic Variants Detected } \\
\mathrm{n} \text { (\% of requested tests) }\end{array}$ & Gene (OMIM) & $\begin{array}{c}\text { Gene Variants } \\
\mathrm{n} \text { (\% of identified variants) }\end{array}$ \\
\hline \multicolumn{6}{|c|}{ Total KGC Cohort } \\
\hline & 293 & $125(42.7)$ & $76(60.8)$ & - & - \\
\hline \multicolumn{6}{|c|}{ Phenotype } \\
\hline ADPKD & 181 & $39(21.5)$ & $28(71.8)$ & $\begin{array}{c}\text { PKD1 (601313) } \\
\text { GANAB (104160) } \\
\text { PKD2 (173910) }\end{array}$ & $\begin{array}{l}25(89.3) \\
2(7.1) \\
1(3.6)\end{array}$ \\
\hline AS & 20 & $15(75)$ & $11(73.3)$ & $\begin{array}{l}\text { COL4A5 (303630) } \\
\text { COL4A3 (120070) } \\
\text { COL4A4 (120131) }\end{array}$ & $\begin{array}{l}8(72.7) \\
2(18.2) \\
1(9.1)\end{array}$ \\
\hline FSGS & 18 & $15(83.3)$ & $7(46.7)$ & $\begin{array}{c}\text { COL4A3 }(120070) \\
\text { TRPC6 }(603652) \\
\text { COL4A5 (303630) } \\
\text { ACTN4 }(604638) \\
\text { TMTC3 (617218) }\end{array}$ & $\begin{array}{l}2(28.55) \\
2(28.55) \\
1(14.3) \\
1(14.3) \\
1(14.3)\end{array}$ \\
\hline ADTKD & 14 & $13(92.9)$ & $2(15.4)$ & UMOD (191845) & $2(100)$ \\
\hline aHUS & 13 & $13(100 \%)$ & $5(38.5)$ & $\begin{array}{l}\text { CFH (134370) } \\
\text { C3 (120700) }\end{array}$ & $\begin{array}{l}4(80) \\
1(20)\end{array}$ \\
\hline TSC & 10 & $7(70)$ & $7(100)$ & $\begin{array}{l}\text { TSC2 (191092) } \\
\text { TSC1 (605284) }\end{array}$ & $\begin{array}{l}5(71.4) \\
2(28.6)\end{array}$ \\
\hline FRG & 7 & $6(85.7)$ & $5(83.3)$ & SLC5A2 (182381) & $5(100)$ \\
\hline GS & 5 & $0(0)$ & - & - & - \\
\hline dRTA & 3 & $3(100)$ & $3(100)$ & SLC4A1 (109270) & $3(100)$ \\
\hline BS & 3 & $3(100)$ & $3(100)$ & $\begin{array}{l}B S N D(606412) \\
\text { CLCNKB (602023) }\end{array}$ & $\begin{array}{l}2(66.7) \\
1(33.3)\end{array}$ \\
\hline Others & 19 & $11(57.9)$ & $5(45.5)$ & $\begin{array}{c}\text { MVK (51170) } \\
\text { RMND1 (614917) } \\
\text { AVPR2 (00538) } \\
\text { NF1 (613113) } \\
\text { NPHP1 (607100) }\end{array}$ & $\begin{array}{l}1(20) \\
1(20) \\
1(20) \\
1(20) \\
1(20)\end{array}$ \\
\hline
\end{tabular}

\section{Figure 2}

Examples of axial (A), coronal (B) and sagittal (C) right kidney measurements.
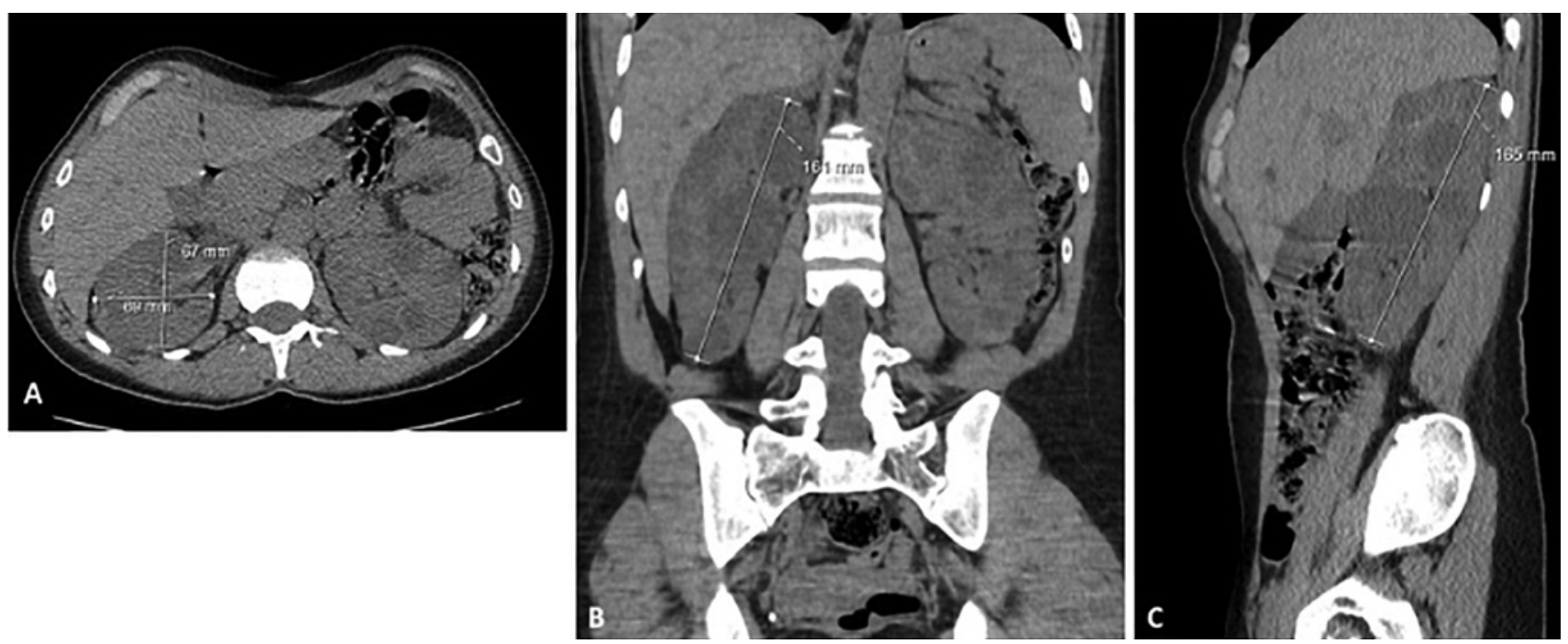


\section{Figure 3}

AML combined volume evolution in a patient before, during and after EVR treatment. Illustrative MRI findings are included.
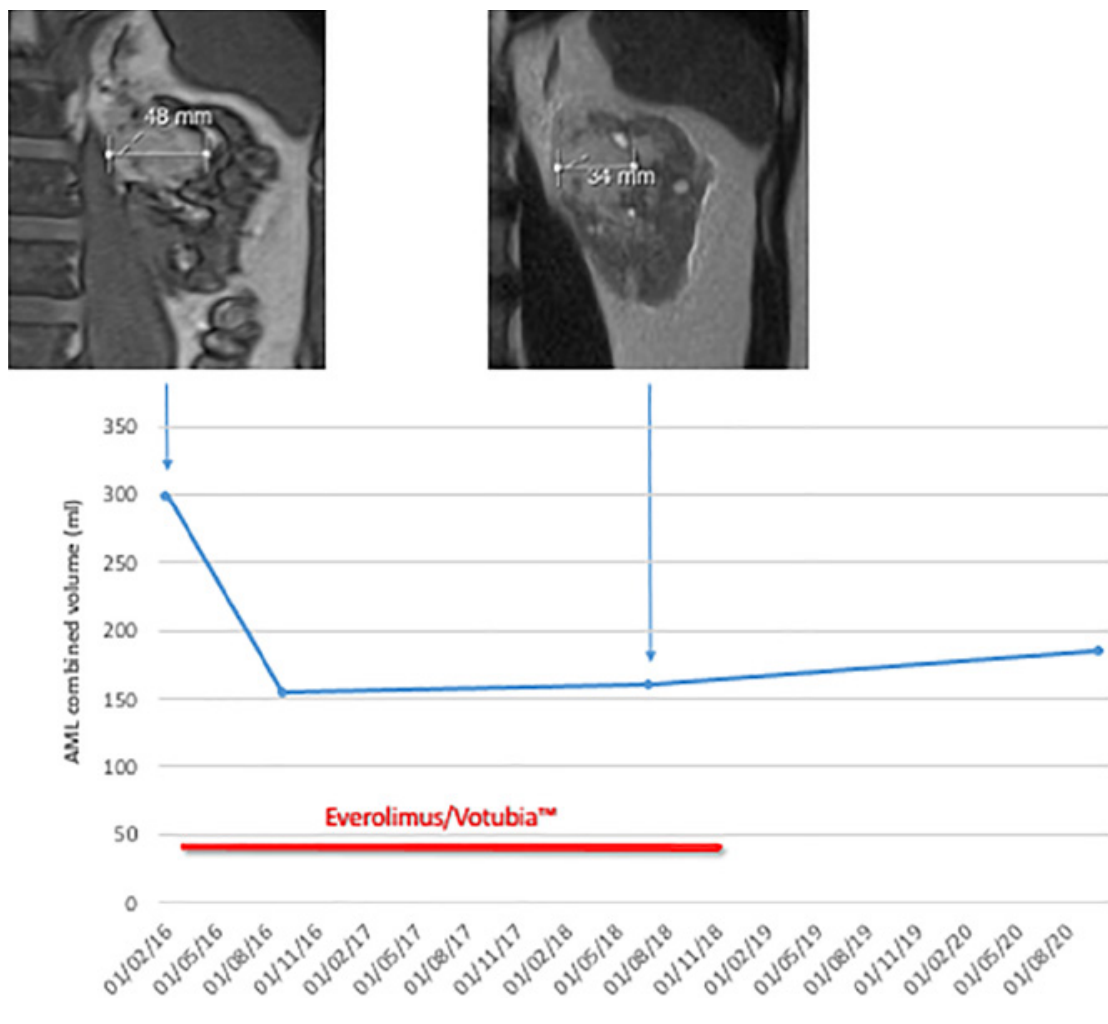

\section{Table 3}

Ht TKV in ADPKD.

\begin{tabular}{c|c|c|c|c}
$\begin{array}{c}\text { Age } \\
\text { (years) }\end{array}$ & $\begin{array}{c}\text { Gender } \\
(\mathrm{M} / \mathrm{F})\end{array}$ & $\begin{array}{c}\text { Screat. } \\
(\mathrm{mg} / \mathrm{dl})\end{array}$ & $\begin{array}{c}\text { ht TKV } \\
(\mathrm{ml} / \mathrm{m})\end{array}$ & $\begin{array}{c}\text { Mayo } \\
\text { Classification }\end{array}$ \\
\hline 62 & $\mathrm{~F}$ & 1.66 & 742.7 & $1 \mathrm{C}$ \\
46 & $\mathrm{M}$ & 1.8 & 3167.7 & $1 \mathrm{E}$ \\
\hline 36 & $\mathrm{~F}$ & 0.66 & 661.7 & $1 \mathrm{C}$ \\
\hline 47 & $\mathrm{~F}$ & 0.7 & 1045 & $1 \mathrm{C}$ \\
\hline 55 & $\mathrm{~F}$ & 0,78 & 315 & $1 \mathrm{~A}$ \\
41 & $\mathrm{~F}$ & 0.6 & 178.1 & $1 \mathrm{~A}$
\end{tabular}

Screat. - serum creatinine; Ht TKV - height adjusted total kidney volume.

As expected for an adult population, the cohort is mostly comprised $(60.8 \%)$ of ADPKD individuals. Genetic testing for ADPKD is seldom requested in clinical practice and, accordingly, only $21.5 \%$ of our ADPKD patients underwent molecular diagnosis. Also, our detection rate of pathogenic/likely pathogenic variants is $71.8 \%$, not different from that reported in the literature ${ }^{14}$. Collagen type IV-related nephropathies account for the second largest group of individuals evaluated. They presented either as AS $(n=20)$ or as an FSGS phenocopy ${ }^{2}$, with a high rate of pathogenic/likely pathogenic variant detection rate (73.3\% for AS). Interestingly, for AS,

\section{Table 4}

Everolimus/Notubia ${ }^{\text {TM }}$ in TSC.

\begin{tabular}{c|c|c|c}
$\begin{array}{c}\text { Age } \\
\text { (years) }\end{array}$ & $\begin{array}{c}\text { Gender } \\
\text { (M/F) }\end{array}$ & Gene & $\begin{array}{c}\text { Variant found in } \\
\text { heterozigocity }\end{array}$ \\
\hline 60 & M & TSC2 & $\begin{array}{c}\text { c.3581G>A } \\
(\text { p.Trp1194*) }\end{array}$ \\
23 & F & - & - \\
21 & F & TSC2 & $\begin{array}{c}\text { c.2441T>C } \\
\text { (p.Leu808Ser) }\end{array}$ \\
18 & M & - & -
\end{tabular}

\section{Table 5}

Eculizumab/Soliris ${ }^{\top M}$ in aHUS.

\begin{tabular}{c|c|c|c|c}
$\begin{array}{c}\text { Age } \\
\text { (years) }\end{array}$ & $\begin{array}{c}\text { Gender } \\
\text { (M/F) }\end{array}$ & Gene & $\begin{array}{c}\text { Variant found } \\
\text { in heterozigocity }\end{array}$ & Reason for Relapse \\
\hline 42 & $\mathrm{M}$ & $\mathrm{CFH}$ & $\mathrm{c.3661G>T;(p.Gly1221Trp)}$ & $\begin{array}{c}\text { ECZ discontinuation } \\
\text { Previous remission } \\
\text { with plasma }\end{array}$ \\
45 & $\mathrm{~F}$ & wt & - & $\begin{array}{c}\text { ECZ discontinuation } \\
41\end{array}$ \\
\hline
\end{tabular}

wt - no pathogenic variants detected; ECZ - eculizumab. 


\section{Table 6}

Tolvaptan/Jinarc ${ }^{T M}$ therapy in ADPKD.

\begin{tabular}{c|c|c|c|c|c}
$\begin{array}{c}\text { Age } \\
\text { (years) }\end{array}$ & $\begin{array}{c}\text { Gender } \\
\text { (M/F) }\end{array}$ & $\begin{array}{c}\text { Screat. } \\
\text { (mg/dl) }\end{array}$ & Ht TKV (Mayo) & Gene/(Allele) & $\begin{array}{c}\text { Selection } \\
\text { Criteria }\end{array}$ \\
\hline 36 & $\mathrm{~F}$ & $\mathbf{0 . 6 6}$ & $\mathbf{6 6 1 . 7}(\mathbf{1 C})$ & - & Ht TKV \\
46 & $\mathrm{M}$ & $\mathbf{1 . 8}$ & $\mathbf{3 1 6 7 . 7 ( 1 \mathrm { E } )}$ & - & eGFR \\
31 & $\mathrm{~F}$ & 0.7 & - & PKD1/(Arg1672Glyfs*98) & PRO-PKD score \\
38 & $\mathrm{M}$ & 1.49 & - & - & eGFR
\end{tabular}

In bold are highlighted the patients who have already initiated tolvaptan at the time of writing of the manuscript. * see reference ${ }^{19}$ for details.

\section{Table 7}

Most frequently outsourced genetic testing facilities.

\begin{tabular}{c|c} 
Academic & Commercial \\
\hline $\begin{array}{c}\text { Departamento de Hematologia } \\
\text { Centro Hospitalar e Universitário } \\
\text { de Coimbra }\end{array}$ & GENOMED \\
Serviço de Genética & Diagnósticos de Medicina Molecular SA \\
Faculdade de Medicina da Universidade & Genética Médica \\
do Porto & CGC Genetics (Unilabs) \\
\hline
\end{tabular}

the female gender predominates. Although some autosomal forms may account for this, we have observed that even for X-linked AS pedigrees, more female $(n=6)$ than man $(n=2)$ were being tested. One possible explanation is that sisters, daughters or mothers of affected male patients were being evaluated due, for instance, to hematuria. The third most frequent phenotype in our list is ADTKD, with a mutation detection of $15.4 \%$. KGC ADTKD patients are part of our single-center ADTKD registry that includes 25 individuals and has a similarly low rate of variant detection. For the interested reader, these are all included in the international UMOD Mutation Registry (http://j.mp/2q7Fi8f) ${ }^{15}$. As previously mentioned, in earlier years, we only sequenced the UMOD gene in FJHN pedigrees. More recently, a broader definition of ADTKD was introduced to accommodate the finding of loci heterogeneity and we are now able to request for REN, SEC61A and HNF1B (including HNF1B major DNA rearrangements). These 3 genes, however, account for a small minority of cases. Other than UMOD, reported in the literature to be responsible for $38.4 \%$ of ADTKD families, the other single relevant gene is MUC1, with a cytosine insertion occurring in the VNTR (variable number tandem repeats) of its coding region found in $35.1 \%$ of the ADTKD-UMOD negative pedigrees ${ }^{16}$. Detection of the MUC1 insertion remains technically challenging and should be only pursued after having first sequenced $U M O D$. The $13 \mathrm{KGC}$ patients with aHUS are also part of a larger single center registry that includes 41 patients and the observed $38.5 \%$ mutation detection rate is not different from the found for the whole registry (32\%), but much lower than the $50-60 \%$ figure generally reported ${ }^{8}$. The multigene panel tested in use already includes 11 genes coding for proteins regulating the alternative complement pathway. Contrary to ADTKD, in which a family history is a major diagnostic criterion, in aHUS the family history is rarely (if ever) present. Also, the registry of CHULC of adult aHUS patients is gene test driven and includes patients who were evaluated in the pre-transplant setting with chronic kidney disease (CKD) of unknown etiology but in whom, and retrospectively, thrombotic microangiopathy (TMA) could not have been excluded and were, therefore, eligible for genetic screening. Realistically, only a fraction of those would have had TMA and even though, probably secondary in its nature.

The identification of pathogenic/likely pathogenic variants in relevant genes enables the nephrologist to "molecularly" establish a diagnosis. From our experience, this turned out to be relevant in the following circumstances:

i) Typical phenotypes with atypical patterns of inheritance (e.g., autosomal AS);

ii) Atypical/incomplete phenotype expression in sporadic cases of a mendelian trait (e.g., de novo ADPKD);

iii) A substitute for renal biopsy in tubulo-interstitial disease with or without family history (e.g., ADTKD, NPH);

iv) Ascertaining the correct etiology in face of non-specific histopathological findings (e.g., FSGS);

Overlapping with these and in the particular setting of renal transplantation, an informative genetic test was relevant because it:

v) Enabled living related kidney donation (e.g., NPH);

vi) Correctly assessed the risk of disease recurrence (e.g., genetic forms of FSGS (no risk), aHUS (high risk).

The Pharmaceutical Department of CHULC can now provide Tolvaptan/Jinarc ${ }^{\mathrm{TM}}$ for our ADPKD patients. Tolvaptan/Jinarc ${ }^{\mathrm{TM}}$ was approved for the treatment of rapidly progressive forms of ADPKD following the TEMPO trials ${ }^{17,18}$. European (eGFR centered) and American (ht TKV based) guidelines are available ${ }^{19,20}$ and they provided the frame for the treatment protocol we have implemented in CHULC (available on request). Tolvaptan/Jinarc ${ }^{\mathrm{TM}}$ is the first approved medicine for ADPKD. Novel therapies are also emerging and the future looks bright for upcoming ADPKD generations. Unfortunately, the future also comes with an expensive price tag. ADPKD is not a rare disease. Using a population sequencing methodology, prevalence estimates are of $9.3 / 10000^{21}$. If one considers the population for which CHULC provides nephrology care $(360000$ in Lisbon +250000 in Vila Franca de Xira) one can assume that there are 567 individuals with ADPKD in that population alone. Selecting and providing specific therapies for the ADPKD population will cause a heavy burden on nephrology departments because referrals must now occur long before serum creatinine rises. In addition to the medicine cost, one has to anticipate the imaging procedures as well a more widespread use of genetic testing that will be needed for proper risk stratification. Finally, if the patient is selected for treatment, monthly visits are scheduled for the first 1.5 years of treatment, in striking contrast to the current practice of every-other-year appointment or no appointments at all (for those with normal serum creatinine). We have already started to prioritize patients for Tolvaptan/Jinarc ${ }^{\mathrm{TM}}$ treatment approval in 2022. The initial feverish enthusiasm of getting our first patients treated in 2021 has given place to ethical concerns on who will 
not get it in next coming years. Importantly, and aware that our views may not be representative of the nationwide nephrology community, it is imperative that we reach a national consensus for ADPKD current and future treatments, in order to prevent discrepancies in patients' access to therapy.

Our study has several limitations. It did not evaluate the costs of genetic testing or those related to disease specific medicines. Also, we have not detailed the turnaround times for genetic testing. Finally, by characterizing patients and not pedigrees, we probably overestimated the prevalence of some rare phenotypes and alleles, and incurred in gender distribution bias, as already mentioned for X-linked AS.

But regardless of the above-mentioned limitations, this analysis enabled us to assume the following considerations. First, that even in the absence of an affiliated genetic laboratory, it is still possible to provide patients with molecular genetics testing. Second, that patients are best served by physicians who see a high volume of cases like theirs, this being particularly true when it comes to rare and orphan diseases. In fact, deploying precision medicine tools (diagnostic as well therapeutics) was only possible because of the KGC enrichment nature of the referral. Third, that genetic testing performed outside formal genetic counselling or research scopes ought to primarily concern cases that remain unsolved after non-invasive clinical/phenotype evaluation. This will allow us, in the future, to focus on novel approaches like whole exome sequencing as exemplified by a recent report that established a mendelian cause in almost $10 \%$ of CKD cases of unknown etiology 22 . Lastly, that collaborative work between pediatric and adult nephrologists sharing a common interest in inherited kidney disorders is the best way to approach familial disorders and ensure proper continuity of treatment for pediatric patients.

In the adult nephrology environment, molecular genetics only seldom impacts on formal genetic counselling. Still, and as hereby exemplified, genotype information often provides the best way nephrologists can reach precision diagnostics and personalized therapeutics. There are 2 additional areas for which genetics and Genomics are revolutionizing nephrology. The first one concerns the more prevalent complex/multifactorial traits such as the African-American populations' susceptibility to CKD, where APOL1 alleles play a major role ${ }^{23}$. The other being gene therapies, like those based on siRNA platforms, in particular Lumasiran, an siRNA already approved for patients with Primary Hyperoxaluria, but only for those displaying pathogenic variants in the AGXT gene ${ }^{24}$.

Transitioning from the 40-year-old Evidence Based Medicine into modern day Precision Medicine (patient-centered) will only be possible if we become knowledgeable about Genomics concepts and lexicon. For the next generation of nephrologists, understanding the Genomic basis of kidney diseases (either monogenic or complex/ multifactorial in their nature) will be more relevant than the study of renal histopathology. Revising and updating nephrology fellowship curricula is mandatory in order to overcome present-day medical illiteracy on this subject. If we want our patients to have a glimpse of the future, we must stop looking to the past. The time has come to move forward.

\section{Acknowledgments}

We are indebted to all the fellows who have referred patients and their families. We are grateful to Dr João Paulo Oliveira and Dra Teresa Fidalgo for the fruitful discussions on the AS and aHUS cases, respectively. We want to express our gratitude to patients and their families. Finally, to our nursing staff who were always available to collect biological samples and, in particular, to Ms. Joana Mendes for her outstanding administrative support.

\section{Disclosure of potential conflicts of interest: none declared.}

\section{References}

1. Brum S, Ribeiro NC, Santos AR, Nolasco F, Calado J. Monitorização do volume renal por tomografia computorizada na Doença Poliquística Renal Autossómica Dominante (Encontro Renal abstract SE120). Port J Nephrol Hypert. 2008; 22(1):65-131

2. Serra AL, Poster D, Kistler AD, et al. Sirolimus and kidney growth in autosomal dominant polycystic kidney disease. N Engl J Med. 2010; 363(9):820-829

3. Saunier S, Calado J, Benessy F, et al. Characterization of the NPHP1 locus: mutational mechanism involved in deletions in familial juvenile nephronophthisis. Am J Hum Genet. 2000; 66(3):778-789. doi: $10.1086 / 302819$

4. Santer R, Calado J. Familial renal glucosuria and SGLT2: from a Mendelian trait to a therapeutic target. Clin J Am Soc Nephrol. 2010; 5:133-141

5. Alves M, Fonseca T, de Almeida E. Differential diagnosis of Autosomal Dominant Polycystic Kidney Disease. In: Li X, editor. Polycystic Kidney Disease [Internet]. Brisbane: Codon Publications; 2015 Nov. Chapter 1

6. Nabais Sá MJ, Sampaio S, Oliveira A, et al. Collagen type IV-related nephropathies in Portugal: pathogenic COL4A5 mutations and clinical characterization of 22 families. Clin Genet. 2015 Nov 88(5):462-467. doi: 10.1111/cge.12522.

7. Eckardt KU, Alper SL, Antignac C, et al. Kidney Disease: Improving Global Outcomes. Autosomal dominant tubulointerstitial kidney disease: diagnosis, classification, and management - A KDIGO consensus report. Kidney Int. 2015 Oct; 88(4):676-683. doi: 10.1038/ki.2015.28.

8. Azevedo A, Faria B, Teixeira C, et al. Portuguese consensus document statement in diagnostic and management of atypical hemolytic uremic syndrome. Port J Nephrol Hypert. 2018; 3:1-22

9. Crino PB, Nathanson KL, Henske EP. The tuberous sclerosis complex. N Engl J Med. 2006 Sep; 355(13):1345-1356 doi: 10.1056/NEJMra055323.

10. Blanchard A, Bockenhauer D, Bolignano D, et al. Gitelman syndrome: consensus and guidance from a Kidney Disease: Improving Global Outcomes (KDIGO) Controversies Conference. Kidney Int. 2017 Jan; 91(1):24-33. doi: 10.1016/j.kint.2016.09.046.

11. Konrad M, Nijenhuis T, Ariceta G, et al. Diagnosis and management of Bartter syndrome: executive summary of the consensus and recommendations from the European Rare Kidney Disease Reference Network Working Group for Tubular Disorders. Kidney Int. 2021 Feb; 99(2):324-335. doi: 10.1016/j.kint.2020.10.035.

12. Richards S, Aziz N, Bale S, et al. Standards and guidelines for the interpretation of sequence variants: a joint consensus recommendation of the American College of Medical Genetics and Genomics and the Association for Molecular Pathology. Genet Med. 2015 May; 17(5):405-424. doi: 10.1038/gim.2015.30.

13. Lundquist LP, Pelletier RC, Leonard CE, et al. From theory to reality: establishing a successful kidney genetics clinic in the outpatient setting. Kidney360. 2020, 1099-1106. doi: 10.34067/ KID.0004262020

14. Cornec-Le Gall E, Torres VE, Harris PC. Genetic complexity of autosomal dominant polycystic kidney and liver diseases. J Am Soc Nephrol. 2018 Jan; 29(1):13-23. doi: 10.1681/ASN. 2017050483.

15. Kidd K, Vylet'al P, Schaeffer C, et al. Genetic and clinical predictors of age of ESKD in individuals with autosomal dominant tubulointerstitial kidney disease due to UMOD mutations. Kidney Int Rep. 2020 Jul 3; 5(9):1472-1485. doi: 10.1016/j.ekir.2020.06.029.

16. Olinger E, Hofmann P, Kidd K, et al. Clinical and genetic spectra of autosomal dominant tubulointerstitial kidney disease due to mutations in UMOD and MUC1. Kidney Int. 2020 Sep; 98(3):717-731. doi: 10.1016/j.kint.2020.04.038.

17. Torres VE, Chapman AB, Devuyst O, et al. Tolvaptan in patients with autosomal dominant polycystic kidney disease. N Engl J Med. 2012; 367(25):2407-2418

18. Torres VE, Chapman AB, Devuyst $O$, et al. Tolvaptan in later-stage autosomal dominant polycystic kidney disease. N EngI J Med. 2017; 377(20):1930-1942

19. Gansevoort RT, Arici M, Benzing T, et al. Recommendations for the use of tolvaptan in autosomal dominant polycystic kidney disease: a position statement on behalf of the ERA-EDTA Working Groups on Inherited Kidney Disorders and European Renal Best Practice. Nephrol Dial Transplant. 2016; 31(3):337-348

20. Chebib FT, Perrone RD, Chapman AB, et al. A practical guide for treatment of rapidly progressive DRPAD with tolvaptan. J Am Soc Nephrol. 2018; 29(10):2458-2470

21. Lanktree MB, Haghighi A, Guiard E, et al. Prevalence estimates of polycystic kidney and liver disease by population sequencing. J Am Soc Nephrol. 2018 Oct; 29(10):2593-2600. doi: 10.1681/ ASN.2018050493. 
22. Groopman EE, Marasa M, Cameron-Christie S, et al. Diagnostic utility of exome sequencing for kidney disease. N Engl J Med. 2019; 3

23. Kao WH, Klag MJ, Meoni LA, et al. MYH9 is associated with nondiabetic end-stage renal disease in African Americans. Nat Genet. 2008 Oct; 40(10):1185-1192. doi: 10.1038/ng.232.

24. Garrelfs SF, Frishberg $\mathrm{Y}$, Hulton SA, et al. Lumasiran, an RNAi therapeutic for primary hyperoxaluria type 1. N Engl J Med. 2021 Apr 1; 384(13):1216-1226. doi: 10.1056/NEJMoa2021712.

\section{ORCID}

Joaquim Calado (iD) 0000-0002-1194-3392

Rui Barata (iD) 0000-0001-9860-2517

Rita Lucas (iD) 0000-0002-2979-3003

Telma Francisco (iD) 0000-0002-8232-6818

Nuno Carrilho Ribeiro iD 0000-0002-9212-6756

Fernando Nolasco (iD) 0000-0002-7089-1975

\section{Correspondence to:}

Joaquim Calado

E-mail: jcalado@nms.unl.pt

Rui Barata

E-mail: rui.f.barata@gmail.com 